EXTENDED REPORT

\title{
Subthreshold micropulse diode laser treatment in diabetic macular oedema
}

\author{
M L Laursen, F Moeller, B Sander, A K Sjoelie
}

Br J Ophthalmol 2004;88:1173-1179. doi: 10.1136/bjo.2003.040949

See end of article for authors' affiliations

....................

Correspondence to: Majbrit Lind Laursen, MD, Department of Ophthalmology, Odense University Hospital, DK5000, Odense C

Denmark; majbrit.lind.

laursen@ouh.fyns-amt.dk

Accepted for publication 1 February 2004

\begin{abstract}
Background/aim: Enlargement of laser scars after retinal argon laser photocoagulation can give rise to deterioration in visual acuity. Subthreshold micropulse diode laser may decrease this risk. The aim of this study was to compare the effectiveness of subthreshold micropulse diode laser $(810 \mathrm{~nm})$ and conventional argon laser $(514 \mathrm{~nm})$ photocoagulation for the treatment of clinically significant macular oedema in diabetic patients.

Methods: 23 eyes of 16 patients were randomised to either treatment. Follow up was conducted for a minimum of 5 months. Changes in visual acuity and macular oedema measured by optical coherence tomography were examined.

Results: Visual acuity remained stable in all treatment groups throughout the observation period. Changes in retinal thickness were small both foveally and perifoveally. In patients with focal macular oedema a significant reduction in retinal thickness $(9 \% \sim-26 \mu \mathrm{m}, \mathrm{p}=0.02)$ was seen foveally 3 months after diode laser photocoagulation.

Conclusion: Subthreshold micropulse diode laser and conventional argon laser treatment showed an equally good effect on visual acuity. Subthreshold micropulse diode laser showed a stabilising or even improving effect on macular oedema. The combination of primary diode laser and supplementary argon laser might be particularly favourable in reducing diabetic macular oedema.
\end{abstract}

T herapeutic retinal photocoagulation has been practised for more than 50 years. Since the initial experiments were carried out by Meyer-Schwickerath in the late 1940s treatment has become gradually more refined, effective, and safe as new wavelengths and treatments have entered clinical practice.

The predominant wavelength used today is the argon green wavelength $(514 \mathrm{~nm})$ and numerous studies have shown the benefit of this laser treatment in eyes with diabetic macular oedema. ${ }^{1-5}$ The Early Treatment Diabetic Retinopathy Study demonstrated that argon laser photocoagulation reduces the risk of severe visual loss in eyes with clinically significant macular oedema by $50 \%{ }^{4}$ Visual acuity does however deteriorate in some cases despite early laser treatment. This may be the result of subretinal fibrosis, ${ }^{6-9}$ subretinal neovascular membranes ${ }^{10}{ }^{11}$ or a progressive enlargement of laser scars. ${ }^{12-14}$

Histological studies have indicated that when applying $810 \mathrm{~nm}$ diode laser pulses of short duration (microseconds) the retinal pigment epithelium is almost solely affected, with little histopathological effect on the outer retina and choriocapillaris. ${ }^{12} 1516$ The above mentioned heat induced complications may consequently be decreased by this treatment. However, the question is whether this new treatment has an equally good effect as conventional argon laser on visual acuity and retinal thickness after treatment of clinically significant macular oedema (CSMO). Furthermore, is this treatment feasible in clinical practice? These were the questions to be answered by this prospective pilot study. Only two previous clinical studies have, to our knowledge, tried to elucidate answers ${ }^{17}{ }^{18}$ neither of which has used the objective method of measuring retinal thickness by optical coherence tomography (OCT).

\section{PATIENTS AND METHODS}

\section{Inclusion and exclusion criterio}

Table 1 shows the inclusion and exclusion criteria used in the study.

\section{The eye examination}

The baseline examination included best corrected visual acuity using an ETDRS visual acuity chart at 4 metres, slit lamp examination, indirect stereoscopic ophthalmoscopy with a $90 \mathrm{D}$ lens, $60^{\circ}$ fundus photography centred on the macula, $40^{\circ}$ stereo photos of macula, intravenous fluorescein angiography (FA), and OCT. The FAs were reviewed by an independent examiner. Diffuse macular oedema was defined as having two or more disc areas of retinal thickening and involving the centre of macula. ${ }^{5}$ Focal oedema was defined as an area of retinal thickening less than two disc areas in diameter not affecting the centre of macula.

Follow up examinations were performed 1, 3, and 6 months after laser treatment. All baseline examinations were repeated with the exception of FA, which was not repeated if the eye was deemed stable and required no further photocoagulation treatment.

\section{Optical coherence tomography}

OCT scanning was performed by one of the authors (MLL) using a Humphrey optical coherence tomography scanner, version 1 (Zeiss Humphrey Instruments, Dublin, CA, USA). Six radial scans centred on the fixation point were performed through a dilated pupil in a spoke pattern. Each scan had a length of $6 \mathrm{~mm}$.

The values of the retinal thickness for each of the 100 interferometric A-scans obtained by the OCT were extracted from the scanning software (version A6.1). As the nerve fibre layer in some cases has an inadequate signal to be detected by the OCT algorithm and retinal membranes and hard exudates may have too high a signal, artefacts occur. These artefacts have been corrected by hand using a ruler. The height of the retina between the front of the nerve fibre layer and the retinal pigment epithelium (RPE) in the area of artefacts

Abbreviations: CSMO, clinically significant macular oedema; FA, fluorescein angiography; OCT, optical coherence tomography; RPE, retinal pigment epithelium 
Table 1 Inclusion and exclusion criteria used in the study

Inclusion criteria

Type I or type II diabetes mellitus

Clinically significant macular oedema (CSMO)*

$\mathrm{HbA}_{1 \mathrm{c}} \leqslant 10.0$

Blood pressure $\leqslant 160 / 100 \mathrm{~mm} \mathrm{Hg}$

Exclusion criteria

Proliferative diabetic retinopathy

Previous laser photocoagulation for diabetic retinopathy

Preretinal or vitreous haemorrhage

Retinal detachment

Significant media opacities

Iris neovascularisation

Previous retinal or intraocular surgery

Cataract extraction or lens implantation within the past 12 months

Glaucoma or other ocular disease interfering with assessment of the

treatment results

*CSMO was documented by biomicroscopy and confirmed by fluorescein angiography (FA) and optical coherence tomography (OCT).

were measured and the distance was converted to a distance on the retinal plane using the standard calibration in the OCT apparatus. For quantitative evaluation the macula was divided into nine ETDRS areas ${ }^{19}$ including a central disc with a diameter of $1000 \mu \mathrm{m}$ and an inner and outer ring, each divided into four quadrants, with diameters of 3000 and $6000 \mu \mathrm{m}$, respectively. The mean thickness of each of the nine areas (Al-A9) was calculated as described by Massin and co-workers. ${ }^{20}$ Left and right eyes were treated as a reflection of each other.

The mean retinal thickness in ETDRS area Al-A9 measured by OCT was assessed in 20 eyes of 20 healthy volunteers (five men and 15 women, mean age 42 years; range 28-67). Results are shown as mean (SD) in figure 1.

Macular oedema at the baseline examination in each EDTRS area was defined as a retinal thickness $\geqslant$ mean value $+2 \mathrm{SD}$ of healthy control eyes. In patients with diffuse oedema the retinal thickness was calculated in ETDRS area $\mathrm{Al}$ and as an average of ETDRS area A2-A9. In patients treated focally the retinal thickness was calculated in ETDRS area $\mathrm{Al}$ in the same manner. In the perifoveal areas (A2-A9)

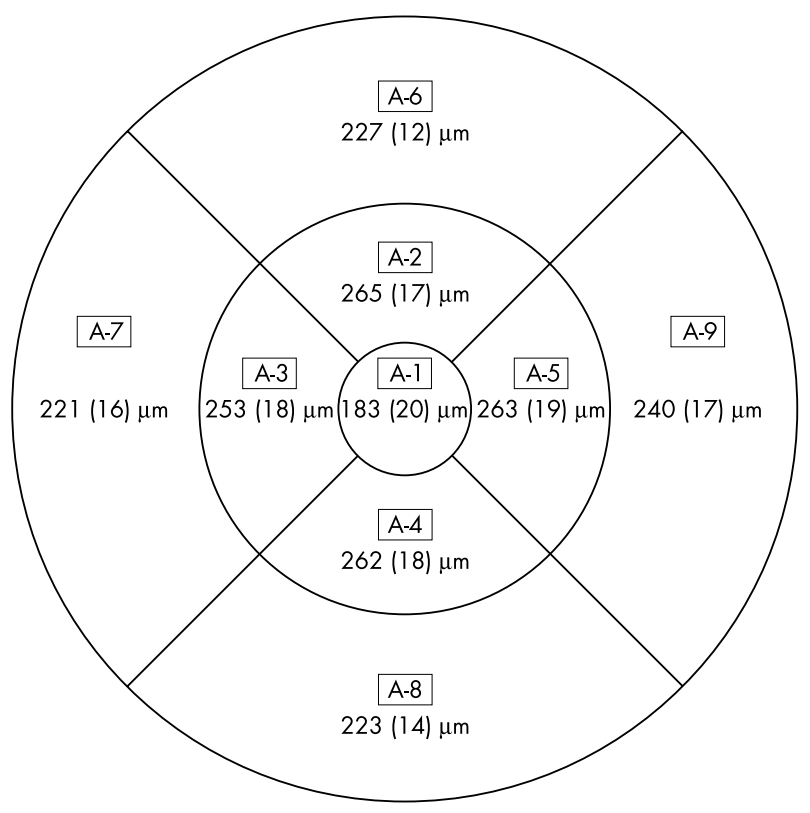

Figure 1 Macular thickness (mean (SD)) in ETDRS areas A1-A9 measured using optical coherence tomography in 20 eyes of 20 healthy individuals. the mean retinal thickness was calculated only for areas with defined oedema at the baseline examination.

The intraobserver reproducibility of the retinal thickness measurement was assessed in 10 eyes of 10 healthy subjects (four men and six women). Six consecutive radial scans were performed three times with at least a 5 minute interval. The mean intrasession coefficient of variation in each ETDRS area is shown in table 2. The mean intrasession coefficient of variation in ETDRS area Al and in area A2 to A9 was 2.6 (1.1) and $0.5(0.2)$ respectively. A significant change in retinal thickness was defined as a change $\geqslant$ mean coefficient of variation $+2 \mathrm{SD}$, which was $4.8 \%$ in ETDRS Al and $0.9 \%$ in area $\mathrm{A} 2-\mathrm{A} 9$.

\section{Randomisation}

Informed consent was obtained from all patients and randomisation was carried out by stratified block randomisation according to the extent of macular oedema to either argon green $(514 \mathrm{~nm})$ or subthreshold micropulse diode laser $(814 \mathrm{~nm})$ treatment. If a patient had both eyes eligible for randomisation, both eyes were randomised independently.

\section{Patients}

Twenty three eyes of 16 consecutive patients referred to the department of ophthalmology at Odense University Hospital with clinically significant diabetic macular oedema as defined by the ETDRS ${ }^{4}$ were recruited for the study over a period of 11 months in 2001.

A flow diagram of patient progress through the study is shown in figure 2 .

\section{Laser treatment}

All patients were treated as outpatients. Written informed consent to the treatment protocol was obtained and the study was approved by the local ethics committee of Fyn and Vejle counties.

After randomisation, laser photocoagulation was applied using either argon green laser (514 nm, Novus 2000, Coherent Inc, Palo Alto, CA, USA) or diode laser $(810 \mathrm{~nm}$, Iris Medical Oculight Slx Laser, Iridex Corp, Mountain View, CA, USA) with an adapter attached to a Haag-Streit slit lamp microscope. Light was focused on the retina using a Mainster Focal/Grid Laser contact lens (Ocular Instruments, Bellevue, WA, USA). The area of macular oedema was treated with standard grid pattern or focal photocoagulation as described by ETDRS. ${ }^{21}$

In patients treated with argon laser a spot size of $100 \mu \mathrm{m}$ was used and the laser applications were placed one spot size apart in the area of retinal thickening. No spots were applied closer to the foveal avascular zone than $500 \mu \mathrm{m}$. A duration of $100 \mathrm{~ms}$ was used and the treatment goal was to keep the

Table 2 Mean coefficient of variation (COV) measuring retinal thickness with optical coherence tomography in ETDRS area A1-A9 in 10 eyes of 10 healthy individuals

\begin{tabular}{ll}
\hline Macular area & $\begin{array}{l}\text { Mean COV } \\
\text { (\%) (SD) }\end{array}$ \\
\hline A1 & $2.92(1.1)$ \\
A2 & $0.86(0.5)$ \\
A3 & $0.69(0.3)$ \\
A4 & $0.83(0.5)$ \\
A5 & $1.30(0.5)$ \\
A6 & $0.66(0.3)$ \\
A7 & $0.90(0.6)$ \\
A8 & $0.78(0.3)$ \\
A9 & $1.37(0.9)$ \\
\hline
\end{tabular}




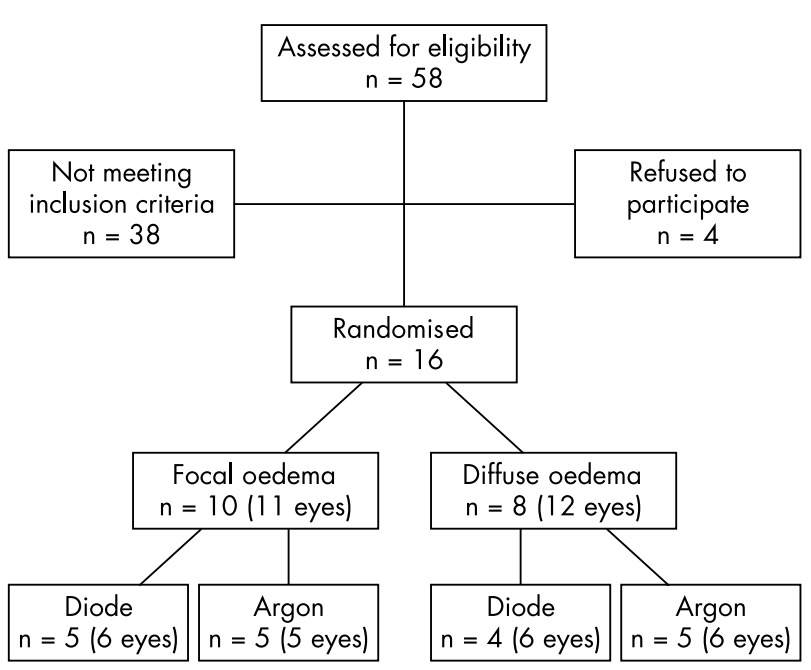

Figure 2 Flow diagram of patient progress through the study.

burns as light as possible, obtaining burns just barely visible at the level of the outer retina. Microaneurysms were treated directly.

Patients randomised to diode laser photocoagulation were treated by one of two observers (MLL or AKS). A spot size of $125 \mu \mathrm{m}$ was chosen. The power was initially adjusted upward to the minimum threshold value for a barely visible burn in normal mode and duration of $100 \mathrm{~ms}$. Then the power was set at half that value and the apparatus was changed to micropulse mode with the "on" time set at $0.1 \mathrm{~ms}(100 \mu \mathrm{s})$ and the "off" time set at $1.9 \mathrm{~ms}(1900 \mu \mathrm{s})$ in a pulse envelope of $2000 \mathrm{~ms}$ duration. As the pigment in the RPE changes over the area of treatment the visible threshold was checked occasionally. In accordance with previously performed studies $^{17}{ }^{18}$ and as diode laser radiation is poorly absorbed by haemoglobin, microaneurysms were not specially targeted.

After 3 months of follow up, supplementary treatment was performed in areas of persistent retinal oedema as judged by stereoscopic indirect ophthalmoscopy and confirmed by FA and OCT (retinal map function).

After treatment the patients were observed by the authors for a minimum of 6 months.

Outcome measures included visual improvement/loss by more than two lines (10 letters) on the ETDRS chart and reduction/elimination of macular oedema evaluated by OCT as previously defined.

\section{Statistics}

Analyses were performed according to the intention to treat principle. Group comparisons were performed with the Mann-Whitney test for independent samples. A two tailed $p$ value of less than 0.05 was considered significant. A nonparametric one way analysis of variance, the Kruskal-Wallis test, was used to test for variance between combinations of treatment. Linear correlation was analysed using the Pearson's product moment correlation coefficient $(r)$ and matching significance of the correlation.

\section{RESULTS}

Fifty eight patients were screened for eligibility. Twenty three eyes of 16 patients were included and followed for 6.5 (SD 1.5) months on average. Patient data are shown in table 3. Information regarding laser treatment and results for each patient is shown in table 4.

During the follow up period one patient (patient 8) had an increase in $\mathrm{HbA}_{1 \mathrm{c}}$ of more than $1 \%$ (from 6.4 to 7.8). This did not affect his visual acuity, which increased form 0.16 to 0.50
(23 letters on the ETDRS chart). His retinal thickness showed no uniform change in that period. Two patients (three eyes) were excluded from the study during the observation period, one on account of proliferative retinopathy, the other because of a cerebral stroke. Two patients had amputations of lower extremities performed during the study.

None of the 23 eyes included had heavily pigmented fundi.

For primary laser photocoagulation the following settings were used (table 5).

Fifteen eyes required further laser photocoagulation after 3 months follow up (nine eyes treated with diode and six eyes treated with argon laser). Supplementary diode laser photocoagulation was only given to three patients. As the subthreshold micropulse diode laser photocoagulation spots were not visible in most eyes on FA after 3 months, and a further 1 month after re-treatment, verification of treatment effect was not possible. Thus in order to comply with the approval from the institutional ethics committee all patients were subsequently re-treated with conventional argon laser.

No laser related complications were observed within the 6 months of observation in either group.

Throughout the study visual acuity was stable (plus or minus 10 letters) in all four treatment groups (table 6). After 3 and 6 months there were no significant differences in visual acuity between the two treatments in patients treated focally or diffusely $(\mathrm{p}>0.05)$.

Comparison of the effect of photocoagulation on retinal thickness in focal and diffuse oedema is shown in table 7. Patients randomised to argon laser photocoagulation for focal oedema had a retinal thickness in area $\mathrm{Al}$ at baseline that on average was $50 \mu \mathrm{m}$ thicker than in the respective diode laser group. This difference was not statistically significant. Regardless of areas (A1, A2-A9) and type of oedema, argon laser gave rise to a small increase in retinal thickness within the first 3 months after laser photocoagulation followed by a decrease during the following 3 months.

After diode laser photocoagulation changes in retinal thickness were more heterogeneous. Patients with focal oedema had a decrease in retinal thickness foveally (area Al) of $9 \%$ (corresponding to $26 \mu \mathrm{m}$ ) 3 months after treatment. This decrease, in percentage terms, was statistically significant compared to argon laser $(p=0.02)$. Conversely, the retinal thickness continuously increased foveally 3 and 6 months after grid treatment. In this group, three patients received supplementary argon laser photocoagulation. Perifoveally (area A2-A9) retinal thickness decreased both 3 months and 6 months after focal and grid diode laser photocoagulation.

\begin{tabular}{ll} 
Table 3 Patient data at baseline & \\
\hline Total no of patients & 16 \\
No of eyes & 23 \\
Males & 14 \\
Females & 2 \\
Type 1 diabetes mellitus & 3 \\
Type 2 diabetes mellitus & 13 \\
Age in years; mean (SD) (range) & $61(13)(39-89)$ \\
Duration of diabetes in years; & $13.6(9.1)(2-37)$ \\
mean (SD) (range) & $146(15)(103-160)$ \\
Systolic blood pressure; & \\
mean (SD) (range) & $81(9)(65-97)$ \\
Diastolic blood pressure; & $10(62.5)$ \\
mean (SD) (range) & $7.5(1.0)(5.9-9.4)$ \\
Number in antihypertensive treatment (\%) & $6(37.5)$ \\
HbA A $_{c ;}$ mean (SD) (range) & \\
History of systemic vascular disease* (\%) &
\end{tabular}

*A history of any of the following conditions: intermittent claudication, amputation of one or more digits, peripheral bypass surgery, cerebral stroke, carotid endarterectomy, carotid bypass surgery, myocardial infarction, or artery bypass surgery. 


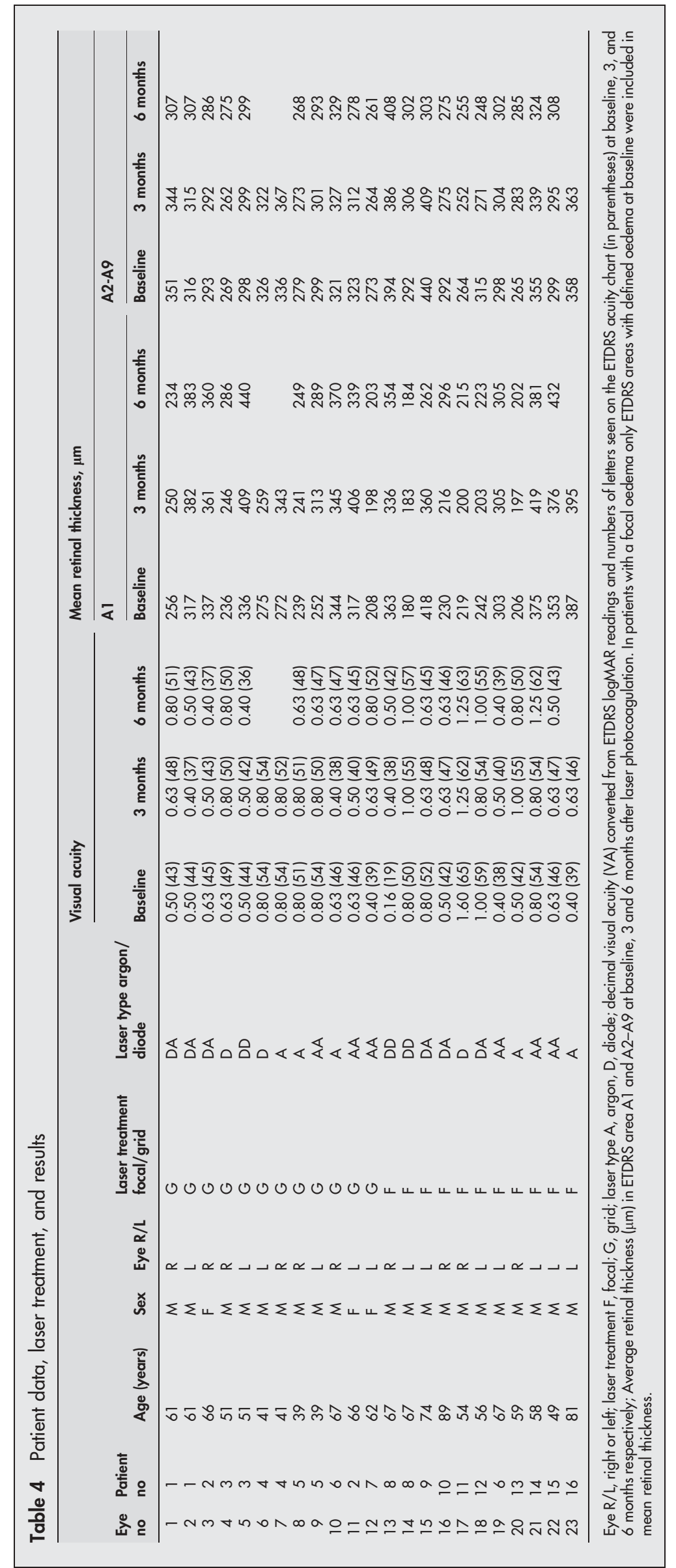




\begin{tabular}{llll|}
\hline Table 5 & Settings & & \\
\hline & & No of applications & Power $(\mathrm{mW})$ \\
\cline { 3 - 3 } Oedema & Treatment & Mean (SD) & Median (range) \\
\hline Diffuse & Diode & $76(18)$ & $500(350-900)$ \\
Diffuse & Argon & $100(25)$ & $105(70-180)$ \\
Focal & Diode & $64(38)$ & $300(190-850)$ \\
Focal & Argon & $65(25)$ & $110(80-130)$ \\
\hline
\end{tabular}

None of the changes in area A2-A9 differed significantly between the two treatment groups (table 7). Pooling results for both types of oedema, thus obtaining a larger number of patients, did not demonstrate any difference in retinal thickness between the two treatments (table 7C).

The effect of treatment combination (one treatment or combinations of argon and/or diode laser photocoagulation) did not differ in focal or diffuse oedema $(\mathrm{p}>0.05)$. Only when comparing all patients treated with diode with all patients treated with argon did the combination of diode-argon treatment seem to be most effective in area $\mathrm{A} 2-\mathrm{A} 9$, and the result almost reached statistical significance $(p=0.05)$.

Pearson's correlation coefficient between foveal retinal thickness and visual acuity in logMAR readings at baseline was $0.20(\mathrm{p}=0.37)$.

\section{DISCUSSION}

The clinical effect of diode laser photocoagulation in the treatment of diabetic macular oedema has been presented in several studies ${ }^{22-26}$ but only a few have used subthreshold ${ }^{27}$ or subthreshold and micropulse settings. ${ }^{17}$ All studies agree that the diode laser is effective in reducing macular oedema and stabilising visual acuity and that the effect is comparable to treatment results after argon laser photocoagulation. 222526

Treatment results from the two reported studies using subthreshold micropulse diode laser photocoagulation are difficult to compare with our results as different methods have been employed. Neither of the two studies described have used inclusion or exclusion criteria in order to select patients without confounding ocular or medical diseases. The proportion of patients with pigmented fundi has not been described although it is crucial for the power needed to give effect. $^{26}{ }^{28}$ Also the effect on retinal thickness has been evaluated by different methods in the performed studies. In all previously mentioned studies changes in retinal thickness have been based on stereoscopic biomicroscopy, fundus photographs, and FA, and results have been presented as numbers of patients with reduction/stabilisation or increase in retinal thickness. Slit lamp examination has, in comparison with OCT, proved to be unreliable in detecting an increase in retinal thickness smaller than $250 \mu \mathrm{m} .{ }^{29}$ Further analysis of the blood-retinal barrier with FA may not be sufficient to fully appreciate macular oedema ${ }^{30}$ and only an intermediate relation $(r=0.44, \mathrm{p}=0.01)$ between the average retinal thickness measured by OCT and the leakage score derived from FA has been found in a previous study. ${ }^{31}$

Several studies have demonstrated that OCT is able to measure retinal thickness in diabetic macular oedema objectively and with high accuracy. ${ }^{20}{ }^{32}$ This method has so far not been used to measure treatment effect of diode laser photocoagulation but two studies have demonstrated reduction in foveal thickness after argon laser photocoagulation of CSMO (Rivellese et al; five eyes ${ }^{33}$ and Lattanzio et al; 52 eyes $\left.^{34}\right)$.

In agreement with previously performed studies ${ }^{17} 18$ we found subthreshold micropulse diode laser photocoagulation to have a stabilising effect on visual acuity. The effect on macular oedema measured with OCT was stabilising or even produced improvement. Instead of a single measurement of retinal thickness in the central fovea we used the full length of the six radial scans in order to visualise changes in extrafoveal macular oedema as well. Three months after focal diode laser treatment a significantly beneficial effect was seen in area $\mathrm{Al}$ in comparison with argon laser photocoagulation. After 6 months five out of six patients in this group had received supplementary treatment (three diode and three argon treated) and the difference between the two groups had now disappeared. This might be the result of the increase in retinal thickness observed, especially foveally, after argon laser photocoagulation. The reverse was seen perifoveally, where the combination of primary diode laser and supplementary argon laser photocoagulation seemed to be favourable.

Results from previous studies in patients with diabetic macular oedema ${ }^{35} 36$ have shown correlation coefficients between visual acuity in logMAR readings and the foveal retinal thickness of $r=0.64$ and $r=0.68(p<0.01)$. In the present study we could not confirm a significant correlation on univariate analysis $(r=0.20, \mathrm{p}=0.37)$.

Our patients were recruited from an outpatient clinic with a preponderance of patients with numerous microvascular and macrovascular complications. This was the reason for the many cardiovascular events and exclusion of patients during the observation period.

Table 6 Changes in visual acuity 3 and 6 months after diode or argon laser photocoagulation of focal or diffuse macular oedema

\begin{tabular}{lll}
\hline Focal laser photocoagulation & Diode laser $(\mathbf{n}=6)$ & Argon laser $(\mathbf{n}=5)$ \\
\hline 3 months & $+2.8(-5$ to +19$)$ & $+4.6(0$ to +13$)$ \\
6 months & $+3.5(-7$ to +23$)$ & $+3.5(-3 \text { to }+8)^{*}$ \\
\hline Diffuse laser photocoagulation & Diode laser $(\mathbf{n}=6)$ & Argon laser $(\mathbf{n}=6)$ \\
\hline 3 months & $-0.8(-7$ to +5$)$ & $-1.7(-8$ to +10$)$ \\
6 months & $-1.6(-8$ to +8$)$ & $+0.6(-7 \text { to }+13)^{*}$ \\
\hline${ }^{*} n-1$. All $p$ values are $>0.05$. &
\end{tabular}


Table 7 Changes in retinal thickness

\begin{tabular}{|c|c|c|c|}
\hline \multicolumn{4}{|c|}{ (A) Focal laser photocoagulation: } \\
\hline & Diode laser $(n=6)$ & Argon laser $(n=5)^{*}$ & p Value \\
\hline \multicolumn{4}{|c|}{ ETDRS area $\mathrm{Al}$} \\
\hline Baseline & $275(93) \mu \mathrm{m}$ & $325(74) \mu \mathrm{m}$ & NS \\
\hline 3 months & 250 (77) $\mu \mathrm{m}(-9 \%,-26 \mu \mathrm{m},-58$ to $+3 \mu \mathrm{m})$ & 338 (90) $\mu \mathrm{m}(+4 \%,+13 \mu \mathrm{m},-9$ to $+44 \mu \mathrm{m})$ & 0.02 \\
\hline 6 months & 256 (62) $\mu \mathrm{m}(-7 \%,-20 \mu \mathrm{m},-156$ to $+66 \mu \mathrm{m})$ & $330(100) \mu \mathrm{m}(+2 \%,+5 \mu \mathrm{m},-4$ to $+79 \mu \mathrm{m})$ & NS \\
\hline \multicolumn{4}{|c|}{ ETDRS area A2-A9 } \\
\hline Baseline & $333(68) \mu \mathrm{m}$ & $315(41) \mu \mathrm{m}$ & NS \\
\hline 3 months & $317(65) \mu \mathrm{m}(-5 \%,-16 \mu \mathrm{m},-44$ to $+14 \mu \mathrm{m})$ & 317 (33) $\mu \mathrm{m}(+1 \%,+2 \mu \mathrm{m},-16$ to $+18 \mu \mathrm{m})$ & NS \\
\hline 6 months & $298(58) \mu \mathrm{m}(-10 \%,-34 \mu \mathrm{m},-137$ to $+14 \mu \mathrm{m})$ & $305(16) \mu \mathrm{m}(-3 \%,-10 \mu \mathrm{m},-31$ to $+20 \mu \mathrm{m})$ & NS \\
\hline \multicolumn{4}{|c|}{ (B) Grid laser photocoagulation: } \\
\hline & Diode laser $(n=6)^{*}$ & Argon laser $(n=6)^{*}$ & p Value \\
\hline \multicolumn{4}{|c|}{ ETDRS area Al } \\
\hline Baseline & $293(43) \mu \mathrm{m}$ & $272(51) \mu \mathrm{m}$ & NS \\
\hline 3 months & $318(74 \mu \mathrm{m}(+8 \%,+25 \mu \mathrm{m},-16$ to $+73 \mu \mathrm{m})$ & $308(76 \mu \mathrm{m}(+13 \%,+36 \mu \mathrm{m},-10$ to $+89 \mu \mathrm{m})$ & NS \\
\hline 6 months & $341(81 \mu \mathrm{m}(+16 \%,+48 \mu \mathrm{m},-22$ to $+104 \mu \mathrm{m})$ & $290(67 \mu \mathrm{m}(+7 \%,+18 \mu \mathrm{m},-5$ to $+37 \mu \mathrm{m})$ & NS \\
\hline \multicolumn{4}{|c|}{ ETDRS area A2-A9 } \\
\hline Baseline & $309(29) \mu \mathrm{m}$ & $305(26) \mu \mathrm{m}$ & NS \\
\hline 3 months & $306(28) \mu \mathrm{m}(-1 \%,-3 \mu \mathrm{m},-7$ to $+1 \mu \mathrm{m})$ & $307(38) \mu \mathrm{m}(+1 \%,+2 \mu \mathrm{m},-11$ to $+31 \mu \mathrm{m})$ & NS \\
\hline 6 months & 295 (14) $\mu \mathrm{m}(-5 \%,-14 \mu \mathrm{m},-44$ to $+6 \mu \mathrm{m})$ & $286(27) \mu \mathrm{m}(-6 \%,-19 \mu \mathrm{m},-45$ to $+8 \mu \mathrm{m})$ & NS \\
\hline \multicolumn{4}{|c|}{ (C) Focal and grid laser photocoagulation: } \\
\hline & Initial diode laser $(n=12)^{*}$ & Initial argon laser $(n=11)^{*}$ & p Value \\
\hline \multicolumn{4}{|c|}{ ETDRS area $\mathrm{Al}$} \\
\hline Baseline & $284(70) \mu \mathrm{m}$ & $296(65) \mu \mathrm{m}$ & NS \\
\hline 3 months & $284(81) \mu \mathrm{m}(0 \%, 0 \mu \mathrm{m},-58$ to $+73 \mu \mathrm{m})$ & $322(80) \mu \mathrm{m}(+9 \%,+26 \mu \mathrm{m},-10$ to $+89 \mu \mathrm{m})$ & NS \\
\hline \multirow[t]{2}{*}{6 months } & $294(81 \mu \mathrm{m}(+4 \%,+10 \mu \mathrm{m},-156$ to $+66 \mu \mathrm{m})$ & $308(80 \mu \mathrm{m}(+4 \%,+12 \mu \mathrm{m},-5$ to $+79 \mu \mathrm{m})$ & NS \\
\hline & Diode laser $(n=12)^{*}$ & Argon laser $(n=11)^{*}$ & p Value \\
\hline \multicolumn{4}{|c|}{ ETDRS area $\mathrm{A} 2-\mathrm{A} 9$} \\
\hline Baseline & $321(52) \mu \mathrm{m}$ & $310(32) \mu \mathrm{m}$ & NS \\
\hline 3 months & $311(48) \mu \mathrm{m}(-3 \%,-10 \mu \mathrm{m},-44$ to $+14 \mu \mathrm{m})$ & $312(34) \mu \mathrm{m}(+1 \%,+2 \mu \mathrm{m},-16$ to $+31 \mu \mathrm{m})$ & NS \\
\hline 6 months & 297 (42) $\mu \mathrm{m}(-8 \%,-24 \mu \mathrm{m},-137$ to $+14 \mu \mathrm{m})$ & 294 (24) $\mu \mathrm{m}(-5 \%,-15 \mu \mathrm{m},-45$ to $+20 \mu \mathrm{m})$ & NS \\
\hline
\end{tabular}

${ }^{*} n-1$ at 6 months observation. $p$ Values comparing changes in percentage terms were calculated using the Mann-Witney test.

The mean retinal thickness in ETDRS area A1 and A2-A9 at baseline, 3, and 6 months after focal or grid photocoagulation with either diode or argon laser stated as mean (SD). Percentage change, change in $\mu \mathrm{m}$, and range of change compared to baseline examination in parentheses $(\%, \mu \mathrm{m}$, range).

Because of ethical considerations we were unable to follow the patients without supplementary treatment for a longer period of time than reported ( 3 months) before re-treatment. A third untreated control group would have been desirable in order to follow the natural history of changes in retinal thickness among patients with CSMO, but was not considered ethically acceptable.

In clinical practice we found subthreshold micropulse diode laser photocoagulation difficult to use. Laser burns at suprathreshold power only became visible after several seconds, making the correct power settings difficult and time consuming. As treatment applications in subthreshold micropulse mode are invisible, a clear treatment plan is demanded. Recently indocyanine green angiography has been shown precisely to localise subthreshold infrared laser $(810 \mathrm{~nm})$ photocoagulation sites immediately after treatment. ${ }^{37}$ Although this procedure will not make treatment sessions shorter, the method could be advantageous in identifying the location of laser lesions to assess initial therapy, avoid re-treating previously treated sites, and plan additional laser therapy if indicated.

In conclusion, we found subthreshold micropulse diode laser photocoagulation to have an equally good effect on visual acuity as conventional argon laser photocoagulation after 3 and 6 months of observation. After 3 months a significant reduction in macular oedema was seen foveally after focal diode laser treatment. Changes in retinal thickness after grid treatment and 6 months after focal diode laser photocoagulation were not significant. As only a few small studies concerning the effect of subthreshold micropulse diode laser have been performed so far, larger controlled trials are needed if this is to be considered for routine treatment in the future management of diabetic macular oedema.

\section{Authors' affiliations}

M L Laursen, F Moeller, A K Sjoelie, Department of Ophthalmology, Odense University Hospital, DK-5000, Odense C, Denmark B Sander, Department of Ophthalmology, Herlev Hospital, University of Copenhagen, DK-2730, Herlev, Denmark

\section{REFERENCES}

1 Patz A, Schatz H, Berkow JW, et al. Macular edema-an overlooked complication of diabetic retinopathy. Trans Am Acad Ophthalmol Otolaryngol 1973;77:OP34-42.

2 Blankenship GW. Diabetic macular edema and argon laser photocoagulation: a prospective randomized study. Ophthalmology 1979;86:69-78.

3 Olk RJ. Argon green $(514 \mathrm{~nm})$ versus krypton red $(647 \mathrm{~nm})$ modified grid laser photocoagulation for diffuse diabetic macular edema. Ophthalmology 1990;97:1101-12.

4 Early Treatment Diabetic Retinopathy Study Research Group. Photocoagulation for diabetic macular edema. Early Treatment Diabetic Retinopathy Study Report Number 1. Arch Ophthalmol 1985;103:1796-806.

5 Olk RJ. Modified grid argon (blue-green) laser photocoagulation for diffuse diabetic macular edema. Ophthalmology 1986;93:938-50.

6 Fong DS, Segal PP, Myers F, et al. Subretinal fibrosis in diabetic macular edema. Early Treatment Diabetic Retinopathy Study Research Group. ETDRS Report 23. Arch Ophthalmol 1997;115:873-7.

7 Wallow IH, Bindley CD. Focal photocoagulation of diabetic macular edema. a clinicopathologic case report. Retina 1988;8:261-9.

8 Guyer DR, D'Amico DJ, Smith CW. Subretinal fibrosis after laser photocoagulation for diabetic macular edema. Am J Ophthalmol 1992; 113:652-6.

9 Han DP, Mieler WF, Burton TC. Submacular fibrosis after photocoagulation for diabetic macular edema. Am J Ophthalmol 1992;113:513-21. 
10 Lewis $\mathrm{H}$, Schachat AP, Haimann MH, et al. Choroidal neovascularization after laser photocoagulation for diabetic macular edema. Ophthalmology 1990;97:503-10.

11 Varley MP, Frank E, Purnell EW. Subretinal neovascularization after focal argon laser for diabetic macular edema. Ophthalmology 1988:95:567-73.

12 Rutledge BK, Wallow IH, Poulsen GL. Sub-pigment epithelial membranes after photocoagulation for diabetic macular edema. Arch Ophthalmol 1993; 111:608-13.

13 Schatz H, Madeira D, McDonald, et al. Progressive enlargement of laser scars following grid laser photocoagulation for diffuse diabetic macular edema. Arch Ophthalmol 1991;109:1549-51.

14 Lovestam-Adrian M, Agardh E. Photocoagulation of diabetic macular oedema-complications and visual outcome. Acta Ophthalmol Scand 2000;78:667-71.

15 Chong LP, Kohen L, Kelsoe W, et al. Selective RPE damage by micropulse diode laser photocoagulation. Invest Ophthalmol Vis Sci 1992;33(4, suppl).

$16 \mathrm{Kim}$ SY, Sanislo SR, Dalal R, et al. The selective effect of micropulse diode laser upon the retina. Invest Ophthalmol Vis Sci 1996;37(3,suppl).

17 Moorman CM, Hamilton AM. Clinical applications of the micropulse diode laser. Eye 1999;13(Pt 2):145-50.

18 Friberg TR, Karatza EC. The treatment of macular disease using a micropulsed and continuous wave 810-nm diode laser. Ophthalmology 1997; 104:2030-8.

19 Kinyoun J, Barton F, Fisher M, et al. Detection of diabetic macular edema. ophthalmoscopy versus photography-Early Treatment Diabetic Retinopathy Study Report Number 5. The ETDRS Research Group. Ophthalmology 1989;96:746-50.

20 Massin P, Vicaut E, Haouchine B, et al. Reproducibility of retinal mapping using optical coherence tomography. Arch Ophthalmol 2001;119:1135-42.

21 Early Treatment Diabetic Retinopathy Study Research Group. Treatment techniques and clinical guidelines for photocoagulation of diabetic macular edema. Early Treatment Diabetic Retinopathy Study Report Number 2. Ophthalmology 1987;94:761-74.

22 Akduman L, Olk RJ. Diode laser $(810 \mathrm{~nm})$ versus argon green $(514 \mathrm{~nm})$ modified grid photocoagulation for diffuse diabetic macular edema. Ophthalmology 1997; 104: 1433-41.

23 McHugh JD, Marshall J, Ffytche TJ, et al. Initial clinical experience using a diode laser in the treatment of retinal vascular disease. Eye 1989;3(Pt 5): 516-27.
24 Ulbig MW, McHugh DA, Hamilton AM. Diode laser photocoagulation for diabetic macular oedema. Br J Ophthalmol 1995;79:318-21.

25 Tewari HK, Gupta V, Kumar A, et al. Efficacy of diode laser for managing diabetic macular oedema. Acta Ophthalmol Scand 1998:76:363-6.

26 Gupta V, Gupta A, Kaur R, et al. Efficacy of various laser wavelengths in the treatment of clinically significant macular edema in diabetics. Ophthalmic Surg Lasers 2001;32:397-405

27 Akduman L, Olk RJ. Subthreshold (invisible) modified grid diode laser photocoagulation in diffuse diabetic macular edema (DDME). Ophthalmic Surg Lasers 1999;30:706-14.

28 Mainster MA. Decreasing retinal photocoagulation damage: principles and techniques. Sem Ophthalmol 1999;14:200-9.

29 Hee MR, Puliafito CA, Wong C, et al. Quantitative assessment of macular edema with optical coherence tomography. Arch Ophthalmol 1995;113:1019-29.

30 Antcliff RJ, Stanford MR, Chauhan DS, et al. Comparison between optical coherence tomography and fundus fluorescein angiography for the detection of cystoid macular edema in patients with uveitis. Ophthalmology 2000; 107:593-9

31 Goebel W, Kretzchmar-Gross T. Retinal thickness in diabetic retinopathy: a study using optical coherence tomography (OCT). Retina 2002;22:759-67.

32 Hee MR, Puliafito CA, Duker JS, et al. Topography of diabetic macular edema with optical coherence tomography. Ophthalmology 1998;105:360-70.

33 Rivellese M, George A, Sulkes D, et al. Optical coherence tomography after laser photocoagulation for clinically significant macular edema. Ophthalmic Surg Lasers 2000;31:192-7.

34 Lattanzio R, Brancato R, Pierro L, et al. Macular thickness measured by optical coherence tomography (OCT) in diabetic patients. Eur J Ophthalmol 2002;12:482-7.

35 Otani T, Kishi S, Maruyama Y. Patterns of diabetic macular edema with optical coherence tomography. Am J Ophthalmol 1999;127:688-93.

36 Yang CS, Cheng CY, Lee FL, et al. Quantitative assessment of retinal thickness in diabetic patients with and without clinically significant macular edema using optical coherence tomography. Acta Ophthalmol Scand $2001 ; 79: 266-70$.

37 Salvetti P, Rosen JM, Reichel E. Subthreshold infrared footprinting with indocyanine green for localizing low-intensity infrared photocoagulation. Ophthalmic Surg Lasers Imaging 2003;34:44-8. 